\title{
PAPER \\ The active recruitment of health workers: a defence
}

\author{
Javier S Hidalgo
}

\begin{abstract}
Correspondence to Javier S Hidalgo, Jepson School of Leadership Studies, University of Richmond, 28 Westhampton Way, Jepson Hall, Richmond, VA 23173, USA;

hidalgoj@gmail.com
\end{abstract}

Received 6 July 2011 Revised 10 September 2012

Accepted 28 September 2012 Published Online First 30 October 2012

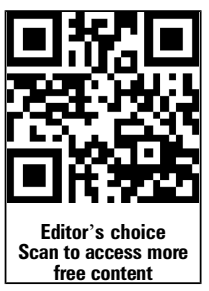

\section{Linked}

- http://dx.doi.org/10.1136/ medethics-2012-101132

- http://dx.doi.org/10.1136/ medethics-2012-101134

- http://dx.doi.org/10.1136/ medethics-2012-101136

- http://dx.doi.org/10.1136/ medethics-2012-101138

- http://dx.doi.org/10.1136/ medethics-2012-101235

- http://dx.doi.org/10.1136/ medethics-2013-101409

To cite: Hidalgo JS. J Med Ethics 2013;39:603-609.

\section{ABSTRACT}

Many organisations in rich countries actively recruit health workers from poor countries. Critics object to this recruitment on the grounds that it has harmful consequences and that it encourages health workers to violate obligations to their compatriots. Against these critics, I argue that the active recruitment of health workers from low-income countries is morally permissible. The available evidence suggests that the emigration of health workers does not in general have harmful effects on health outcomes. In addition, health workers can immigrate to rich countries and also satisfy their obligations to their compatriots. It is consequently unjustified to blame or sanction organisations that actively recruit health workers.

\section{INTRODUCTION}

Many health workers leave poor countries. A large majority of physicians and nurses emigrate from some countries, such as Liberia and Mozambique. ${ }^{1}$ Some people argue that the mass emigration of doctors, nurses, pharmacists and other health workers results in more health-related harms to people in poor states. Poor countries sometimes lack the staff to provide even basic healthcare to their citizens. The mass of emigration of health workers may exacerbate these staff shortages. The governments of poor states also invest considerable resources in training health workers. Governments might lose this investment if health workers emigrate after completing their training.

Health workers emigrate from poor countries in part because organisations in rich countries actively recruit them. There is a strong demand for health workers in rich countries. Their populations are aging and the share of resources that these countries devote to the health sector has rapidly increased in recent decades. Rich states have been unable or unwilling to train enough health workers to meet the demand for these workers. So, businesses, non-profits and governments in these countries actively recruit and hire health workers from the developing world. In 2007, there were 270 companies in the USA that specialise in recruiting nurses from abroad. ${ }^{2}$ The practices of one Canadian company, Shopper Drug Mart, are illustrative. Shopper Drug Mart regularly sends road shows to South Africa in order to recruit and interview pharmacists. Shopper Drug Mart also targets practicing pharmacists and professors of pharmacy for recruitment. The company promises high pay and legal assistance to help pharmacists immigrate to Canada. ${ }^{3}$ Other companies recruit by textmessaging health workers, advertising in local newspapers, and holding workshops and job fairs in low-income countries. ${ }^{4}$

Many bioethicists condemn the active recruitment of health workers. While few bioethicists believe that states should coercively prevent health workers from emigrating, many bioethicists contend that it is seriously wrong for organisations in rich states to actively recruit and hire health workers from poor countries. Bioethicists argue that the active recruitment of health workers contributes to harm and facilitates injustice. ${ }^{5}$ Some authors even contend that the active recruitment of health workers should be an international crime. ${ }^{4}$ I am unaware of a single bioethicist who defends the active recruitment of health workers.

In this paper, I will argue against this consensus. I will defend the active recruitment of health workers from low-income states. More precisely, I aim to do two things. First, I will specify the conditions under which this recruitment is permissible. Second, I will give some reasons to believe that the active recruitment of health workers from poor countries is, in general, permissible. If my argument is correct, it is unjust to blame and sanction organisations for actively recruiting health workers in poor countries. I will proceed as follows. First, I will sketch an account of permissible recruitment. My account holds that it is permissible for an employer to actively recruit and hire a worker if the relevant employment contract is voluntary, fair, and no third party has an urgent moral claim against the contract. Second, I will consider the objection that the active recruitment of health workers facilitates harm to people in poor countries. I will argue that the available empirical evidence indicates that the emigration of health workers often has few harmful effects on other people. Third, I will evaluate and rebut the objection that the active recruitment of health workers causes health workers to violate their special obligations to their compatriots. Finally, I will explore some implications of my arguments for law and professional conduct.

\section{AN ACCOUNT OF PERMISSIBLE RECRUITMENT}

In this section, I will sketch a general account of permissible recruitment and hiring. My account goes like this:

Permissible Recruitment. It is morally permissible for organisation $\mathrm{A}$ to recruit and hire person $\mathrm{B}$ for a job if (i) B voluntarily consents to the employment contract, (ii) the terms of employment and working conditions are fair, and (iii) A's hiring of $\mathrm{B}$ avoids violating the moral claims of any third parties. 
The familiar thought that motivates Permissible Recruitment is the idea that we have moral prerogatives to shape our lives in our own way, even if our choices fail to bring about maximally good consequences for other people. ${ }^{6}$ Morality gives us considerable space to pursue our personal projects and associate with other people. It is, for this reason, morally permissible for people to form a wide variety of different personal and commercial relationships with one another as long as these relationships satisfy minimal moral constraints. In particular, it is permissible to form personal and commercial relationships if these relationships are consensual, satisfy minimal standards of fairness and avoid violating the moral claims of other people by, say, harming them or violating their rights. This applies to employment relationships too. Employers are free to recruit and hire people insofar as doing so satisfies constraints (i-iii) of Permissible Recruitment. When these constraints are satisfied, organisations can permissibly recruit workers.

The more controversial aspect of my account involves the background theories of voluntariness, fairness and claims that we need to make conditions (i-iii) of Permissible Recruitment determinate. I will refrain from attempting to articulate a theory of voluntariness or fair working conditions here. Most people don't object to the active recruitment of health workers on the grounds that the employment contracts are involuntary or that the working conditions of these workers are unfair. After all, many of these immigrants are highly skilled. When health workers immigrate to rich countries, they often receive much higher compensation than they would receive in their native countries and they enjoy better working conditions. So, it is implausible to object to the recruitment of health workers by arguing that their employment contracts are generally unfair. There is also little reason to suspect that their employment contracts are usually involuntary. Critics more commonly argue that the recruitment of health workers infringes on the urgent claims of third parties, particularly the claims of people in poor countries who lack access to decent healthcare. For these reasons, I will set conditions (i) and (ii) aside. I will focus on condition (iii).

I now want to consider two different principles that might explain when the active recruitment of workers violates the claims of third parties. These two principles seem to underlie the objections that many people have to the active recruitment of health workers from the developing world. The first principle appeals to moral reasons to avoid enabling harm. The second principle invokes the idea that it is morally impermissible to facilitate other people's wrongdoing.

The first principle is:

Enabling Harm. Organisation A's recruitment of person B is impermissible if this organisation's recruitment of B causes B to refrain from helping person $\mathrm{C}$ and, as a result, $\mathrm{C}$ suffers serious harm.

The idea here is that we have moral reasons to avoid contributing to harm. We can contribute to bringing about a harmful outcome by enabling this outcome. ${ }^{7}$ An agent enables harm if this agent acts in a manner that prevents one person from helping another person to avoid harm. So, if an agent's actions stop person A from helping person B to avoid harm, then this agent enables harm to person B. Person B may have a justified claim against this agent's actions.

The recruitment of workers can enable harm. An organisation enables harm if this organisation's recruitment of a worker causes this worker to refrain from helping someone else in need. Here is an illustration. Imagine that only one doctor lives in a certain rural town. This doctor, Joel, is extremely skilled and dedicated. Joel provides medical care for many members of the community. A wealthy hospital in another city wants to recruit Joel. But, if Joel leaves, some residents of the town will predictably lack decent medical care and, consequently, these people will be more likely to remain sick or even die. The wealthy hospital continues to try to persuade Joel to leave and Joel eventually accepts the hospital's offer. After Joel leaves, people in the town suffer a greater number of serious health-related harms. In this example, the wealthy hospital's recruitment of Joel enables harm to the residents of the town. The wealthy hospital refrains from directly inflicting harm on these residents. But the hospital is also not merely culpable of an omission or a failure to help the town's residents. Rather, the hospital actively undermines people's access to medical care by recruiting Joel. It is plausible that the hospital's actions wrong the residents of the town.

Critics often seem to implicitly appeal to Enabling Harm in order to object to the active recruitment of health workers from the developing world. These critics allege that organisations in rich countries recruit health workers who would otherwise have provided urgent medical care to other people in poor countries. As a result, people in poor countries may be more likely to lack access to medical care and to suffer more incidents of illness, disability and early death. So, the active recruitment of health workers could enable harmful outcomes by undermining people's access to decent healthcare. The moral reasons against enabling harm might explain why the active recruitment of health workers from poor countries is wrong.

This objection to the recruitment of health workers is consistent with the view that most health workers do nothing morally wrong when they leave their countries. One can coherently argue that organisations in rich countries have moral reasons to refrain from contributing to harmful outcomes by encouraging health workers in poor countries to emigrate and also that it is often permissible for health workers to emigrate. ${ }^{1}$ Yet some bioethicists argue that health workers violate moral obligations when they emigrate as well. Moreover, these authors contend that it is impermissible for organisations in rich countries to facilitate the wrongdoing of health workers by recruiting these workers. This suggests a different objection to the recruitment of health workers. This new objection relies on the following principle:

Facilitating Wrongdoing. Organisation A's recruitment and hiring of person $\mathrm{B}$ is impermissible if $\mathrm{B}$ has an obligation to person C and A's recruitment of B would cause B to violate B's obligation to $\mathrm{C}$.

Facilitating Wrongdoing is motivated by the idea that it is wrong for agent A to contribute to a state of affairs in which person $\mathrm{B}$ violates her obligation to person $\mathrm{C}$, even if $\mathrm{A}$ lacks this obligation to C. An agent who facilitates wrongdoing becomes complicit in this wrongdoing. We have moral reasons to avoid

\footnotetext{
${ }^{1}$ You might say: heath workers have general duties of beneficence to help other people. When health workers emigrate, they violate these duties. But there is a problem with this suggestion. It can be costly for health workers to remain in their countries of origin. They may forsake economic opportunities, greater freedom and security. General positive duties to help other people are sensitive to costs. If I only have a general positive duty to help you and it is very costly for me to help you, I may lack a duty to do so. If this is right, then it is plausible that health workers in poor countries generally do nothing wrong when they emigrate if the only duties at stake are general positive duties. But, as I will suggest below, health workers may also have more stringent special obligations to remain in their countries.
} 
complicity in the wrongdoing of other people. Furthermore, if agent $\mathrm{A}$ induces person $\mathrm{B}$ to violate an obligation to person $\mathrm{C}$, then person $\mathrm{C}$ has a justified claim against A's actions.

How does Facilitating Wrongdoing apply to the recruitment of health workers? Health workers might have special obligations to their compatriots. Special obligations are obligations that we owe to other people in virtue of some specific interaction or relationship that we have with them. Health workers in developing countries often benefit from government programmes. Governments subsidise their education and training. So, it is plausible to believe that the health workers who benefit from government subsidies have duties of reciprocity to return the benefits that they have received from the community. Some people believe that health workers who have benefited from public subsidies have duties to remain in their home countries for at least a limited time in order to satisfy their duties of reciprocity. ${ }^{8}$ When organisations in rich countries actively recruit these workers, they encourage these workers to violate their special obligations to their compatriots. Thus, recruiting organisations facilitate the violation of special obligations. These organisations are complicit in this wrongdoing. Therefore, the citizens of poor countries have justified claims against these organisations.

There may be other reasons why third parties have moral claims against the active recruitment of workers. I will refrain from attempting to provide an exhaustive account of these claims. But Enabling Harm and Facilitating Wrongdoing ground important objections to the active recruitment of health workers. These seem to be the major objections that critics raise against this practice. If the active recruitment of health workers enables harm or encourages health workers to violate their special obligations to their compatriots, then the active recruitment of health workers appears to be wrong. But, on other hand, if the active recruitment of health workers generally refrains from enabling harm or facilitating wrongdoing, then this is a compelling reason to believe that this recruitment satisfies the conditions of Permissible Recruitment. ${ }^{2}$

\section{ENABLING HARM AND EMPIRICAL EVIDENCE}

In this section, I will consider an objection to the active recruitment of health workers from poor countries that invokes Enabling Harm. The argument goes:

1. Organisation A's recruitment of person B is impermissible if this organisation's recruitment of B causes B to refrain from helping person $\mathrm{C}$ and, as a result, $\mathrm{C}$ suffers serious harm.

2. When organisations in rich countries actively recruit health workers from poor countries, these organisations encourage health workers to refrain from helping people in poor countries and, as a result, people in poor countries suffer more incidents of serious harm.

3. So, organisations in rich countries act impermissibly when they actively recruit health workers from poor countries.

\footnotetext{
${ }^{2}$ I will omit discussion of one common objection to the active recruitment of health workers: the objection that this recruitment literally involves theft. This objection holds that, when organizations recruit health workers, they 'steal' these workers from poor countries. I omit discussion of this objection because I believe that this objection is extremely weak. States do not own their citizens. This is the case even if states invest resources in benefiting their citizens. More generally, it is false that if you invest resources in benefiting someone, you come to own this person. If states do not own their citizens, then organisations that recruit them are not engaging in theft.
}

The problem with this argument is premise 2. Although this premise seems plausible at first glance, social scientists in fact disagree about whether the emigration of health workers causes worse health outcomes. In this section, I will survey empirical evidence on the effects of medical emigration. I will argue that the empirical evidence is consistent with the view that the emigration of health workers from poor countries only contributes to health-related harms on net when certain background conditions obtain and, furthermore, these background conditions often fail to obtain. Thus, it appears that premise 2 is often false. If premise 2 is false, then recruiting organisations do not in general enable harm to people in poor countries.

The emigration of health workers is often correlated with worse health outcomes. In an influential study, economists Alok Bhargava and Frederic Docquier find that a doubling of the emigration rate of physicians from countries where the HIV prevalence rate exceeds $3 \%$ of the population is associated with a $20 \%$ increase in adult deaths from AIDS (interestingly, the study also finds that the emigration of physicians is uncorrelated with decreases in life expectancy and that the emigration of physicians is actually negatively correlated with adults deaths when less than $3 \%$ of the population is infected with HIV). ${ }^{9}$ We might conclude from this association that the increase in deaths and increased rates of emigration are causally related.

But this inference would be too quick. One problem with this inference is that HIV/AIDS pandemics may also motivate health workers to emigrate. AIDS is a leading cause of death among health workers. So, large percentages of healthcare staff in sub-Saharan African countries understandably report feeling stressed about caring for HIV/AIDS patients. This stress could motivate more health workers to emigrate. If an HIV/AIDS pandemic causes health workers to emigrate, then we are unable to simply assume that this emigration results in more deaths, as the pandemic might jointly explain why there are more deaths and also why more people choose to emigrate. In the absence of evidence of causal effects, we are unable to justifiably conclude that the emigration of physicians results in more deaths. There could be a spurious correlation between more deaths and emigration rates.

So, we need to estimate the causal impact of medical emigration. Only a few studies try to do this. In one important study, economist Michael Clemens uses quasi-natural experiments to test the impact of medical emigration from Africa. These experiments exploit the size of countries in Africa and the colonial division of the continent. Smaller countries have fewer professional opportunities for health workers. This affects their motivation to emigrate. When a country is small, more health workers will emigrate, everything else being equal. This allows empirical researchers to estimate the causal effects of emigration because the size of a country is an 'exogenous variable'. That is, it is plausible that the size of a country is causally unrelated to the quality of healthcare or health outcomes.

Another exogenous variable is language. European states divided up Africa into different political units in a more-or-less arbitrary fashion in 18th and 19th centuries. But the colonial division of the subcontinent had effects on language acquisition. As a result of the colonial division of the subcontinent, some health workers speak French and other workers speak English. Language has a significant effect on whether workers emigrate because there are many more opportunities for employment abroad for people who speak English than there are for people who speak French. But linguistic heritage seems unlikely to affect health outcomes. So, language is another independent or exogenous variable. Clemens uses the size of countries and 
linguistic heritage to estimate the causal effects of emigration from Africa. Clemens finds that the emigration of health workers has no significant effects on basic healthcare availability and the total stock of health workers. Clemens also finds the emigration of health workers fails to have significant effects on health outcomes, such as child mortality, the percentage of children under the age of 5 who suffer from diarrhoea and require medical attention, the percentage of people infected by HIV and other outcomes. ${ }^{10}$ Other studies that estimate the causal impact of medical emigration broadly support Clemens' conclusions. They generally find that medical emigration causes no negative effects on health outcomes or small negative effects in some cases (I will discuss these studies below).

Why might the emigration of health workers have small or neutral effects on health outcomes? Many factors influence whether people have access to adequate healthcare and how this access affects health outcomes. These factors include the quality of a country's infrastructure. If a country has poor transportation infrastructure, health workers may be unable to reach people who need medical care. Poor sanitation systems can also make primary care ineffective. Medical supplies and access to pharmaceuticals matters as well. Health workers might be unable to treat patients if they lack the appropriate supplies.

The characteristics of a country's population are also important, such as the general level of literacy and education. One study on the impact of physician emigration on child mortality and vaccination rates concludes that a higher number of physicians in a country is associated with lower child mortality rates only when more than 60 percent of adults are literate. Even when this condition obtains, the negative impact of physician emigration on child mortality and vaccination rates is not statistically significant according some estimates. The authors of the study conclude: 'reducing medical brain drain is likely to have only small benefits for child mortality and vaccination rates' ${ }^{11}$

Another reason that medical migration might have few negative effects on net is that this migration has positive effects that compensate for negative impacts. These positive effects include remittances. Some research suggests that the emigration of health workers does have negative effects on child mortality, but the impact of remittances at least partly compensates for these negative effects. ${ }^{12}$ The option of emigrating abroad also increases the incentive for people to pursue medical training. So, more people become health workers. If the option of emigrating encourages more people to become health workers, then these people can help replace the health workers who leave. There is some evidence that the prospect of emigrating does, in fact, cause more people to become health workers in lowincome countries. ${ }^{13}$

One other important factor that mitigates the negative effects of medical emigration is that other health workers, such assistant medical officers and administrators, provide many basic health services in poor countries. One study finds that the availability of doctors and nurses does not affect the utilisation of many health services in low- income and middle-income countries. The researchers explain this finding by arguing that other workers provide many basic medical services in these countries. $^{14}$ These 'alternative' health workers seem to perform many of the tasks that doctors and nurses perform in rich countries. Consequently, the emigration of doctors and nurses has less of an impact on the provision of basic services than we might otherwise expect.

A critic of medical emigration might concede that other factors besides the presence of more health workers affect health outcomes and argue that the emigration of health workers nonetheless contributes to bad health outcomes. Yet there are cases where the presence of more health workers would probably have negligible effects on health outcomes. If health workers or healthcare providers have misaligned incentives, the presence of more health workers might do little to improve the quality of people's access to healthcare. Here is one suggestive piece of evidence: many health workers in poor countries are unemployed. Despite the fact that half of all nursing positions in Kenya were unfilled in 2005, a third of nurses in Kenya were unemployed. ${ }^{15}$ In Côte d'Ivoire, 35\% of doctors are underemployed. ${ }^{16}$ How is it possible for there to be shortages of health workers and high unemployment rates for doctors and nurses? The WHO explains: “"[p]overty, flawed private labour markets, lack of public funds, bureaucratic red tape and political interference are partly responsible for the underutilization of skilled workers' ${ }^{17}$ These factors discourage healthcare providers from hiring more health workers. It is possible that, under these conditions, the presence of more health workers would fail to improve health outcomes and the quality of services. After all, the healthcare systems of some poor countries are unable to employ many of the health workers who currently live in these countries.

This brief review of the empirical literature on the impact of medical emigration suggests the following three conclusions. First, social scientists disagree about the effects of medical emigration. Some social scientists believe that medical emigration has negative effects, while other researchers conclude that medical emigration has neutral or even positive effects. Second, even the studies that find that medical emigration has negative causal effects generally conclude that these effects are relatively small and that reducing medical emigration would likely have only minor effects on human development indicators. Third, when studies do report that medical emigration has negative effects, these effects are usually conditional on the presence of other factors, such as widespread literacy and competent administration. Sometimes these other factors are absent. Thus, one implication of this empirical literature is that medical emigration from poor countries probably has negative effects only in some cases.

What does this review of the evidence imply for the ethics of the active recruitment of health workers? While there are surely some instances in which the emigration of health workers contributes to harm, the emigration of health workers does not seem to contribute to bad health outcomes on the whole. So, Enabling Harm fails to explain why there is something generally morally problematic about the active recruitment of health workers from poor countries. Organisations in rich countries often do not enable harm when they recruit health workers abroad. Maybe organisations in rich countries, such as governments and non-profit organisations, should do more to promote the health-related interests of the global poor. But there is good reason to doubt that organisations in rich countries can effectively promote the interests of people in poor countries by refraining from recruiting health workers from these countries.

\section{FACILITATING WRONGDOING}

In this section, I will consider another objection to the active recruitment of health workers. This objection appeals to Facilitating Wrongdoing. The objection goes:

1. Health workers in poor countries have special obligations to their compatriots.

2. These special obligations require health workers to remain in their home countries for a period of time instead of emigrating. 
3. When organisations in rich countries actively recruit health workers from poor countries, these organisations encourage these health workers to violate their special obligations to their compatriots.

4. Organisation A's recruitment and hiring of person B is impermissible if $\mathrm{B}$ has a special obligation to person $\mathrm{C}$ and A's recruitment of B would cause B to violate B's special obligation to $\mathrm{C}$.

5. So, organisations in rich countries are acting impermissibly when they actively recruit health workers in poor countries.

Call this: the facilitation argument. Some bioethicists endorse the facilitation argument. Jeremy Snyder says: 'by encouraging migration, [destination communities] facilitate and promote the wrongdoing of migrants who owe a duty of social responsibility to their home communities'. ${ }^{18}$

But the facilitation argument is unsound. In particular, we should reject premises 2 and 3. To explain why we have good reasons to reject these premises, we need to clarify the nature of the special obligations that health workers have to their compatriots. Once we have clarified the nature of these duties, we should conclude that health workers do not typically violate their special obligations when they emigrate. As I noted earlier, most critics of the recruitment of health workers point out that health workers receive benefits from the state in the form of subsidies for their training. Citizens pay taxes in order to provide health workers with these benefits. It is plausible that the receipt of these benefits activates special obligations of some kind. What is the nature of these obligations? I see at least two possibilities. These obligations could be duties of compensation or duties of reciprocity. I will consider each kind of duty in turn.

The benefits that health workers receive are often expensive. Here is an example: the Kenyan public invests about \$48 000 in the medical training of each physician. ${ }^{19}$ So, Kenyan physicians are the beneficiaries of costly training and education. Sometimes, when we impose costs on other people, we owe them compensation. For instance, I impose costs on my neighbour when I negligently break her window. In this case, I owe my neighbour compensation for my actions. Perhaps health workers owe compensation for the costs that they impose on other people through their education and training and, when health workers emigrate, they neglect to satisfy these duties.

But this suggestion seems unpromising. It is false that we owe people compensation whenever we receive costly benefits from them. In particular, we lack duties of compensation to other people if they knowingly and willingly offered us the benefits in question. If a wealthy benefactor knowingly gives me a large sum of money and I do not sign a contract that requires me to perform any specific action in exchange for this money, I lack a duty to compensate my benefactor for the money he has given me. Similarly, states in low-income countries willingly and knowingly provide health workers with expensive medical training. Furthermore, these states do not generally require health workers to remain in the country as a contractual condition of receiving this training, although there are some rare exceptions. ${ }^{20}$ So, health workers who receive costly benefits do not necessarily owe compensation to their states or compatriots. It is true that public officials may hope or expect that health workers remain in the country. But, insofar as it is false that health workers are contractually obligated to remain, they lack duties to compensate their compatriots for breach of contract or for the other costs they impose.

Nonetheless, if health workers receive benefits from their compatriots, they may still owe them duties of reciprocity, even if they lack duties to compensate them. To illustrate, a person may owe a duty of gratitude to her parents for the benefits that they provided her while raising her, even though she clearly lacks a duty to compensate her parents for the costs of providing these benefits. In the same way, health workers may have duties of reciprocity to their compatriots for providing them with important benefits, even if they have no duty to compensate them. This appeal to reciprocity has intuitive force. George Ofori-Amanfo, a professor of paediatric cardiology at Duke Children's Hospital who emigrated from Ghana, said in an interview: 'I do feel guilty sometimes [about emigrating].... Particularly when I look at the investment that the nation has put in me to give me my basic training and what the nation would have expected me to contribute. There's a lot of guilt in that. Some cocoa farmer worked hard to pay his taxes so I can go to school'. ${ }^{21}$ These remarks suggest an implicit appeal to reciprocity. Ofori-Amanfo's compatriots provided him with costly benefits and, when he emigrated, he may have violated duties of reciprocity to them.

Before I proceed, I want to note that there are different kinds of reciprocity. Philosophers distinguish between two kinds of reciprocity: duties of fair play and duties of gratitude. I will first consider fair play and then discuss gratitude. Duties of fair play are duties to contribute to a cooperative scheme when you have accepted benefits from this scheme. More precisely, a duty of fair play is a duty to bear a fair share of the costs of providing a good from which you willingly benefit. Consider the following example. Imagine that Sarah lives in a city that has an efficient public bus system. Sarah regularly uses the bus to go to work. But the buses operate on an 'honour system'. People need to buy their tickets before getting on the bus, but no one checks to see whether passengers bought tickets. ${ }^{22}$ Given that Sarah willingly benefits from the bus system, it seems that it would be wrong for her to neglect to buy tickets. The explanation involves duties of fair play. Sarah has a duty of fair play to pay her fair share of the costs of the bus system.

Fair play might impose duties on health workers. These workers benefit from a good that other people help provide (advanced education and training). So, perhaps health workers are under duties of fair play to their compatriots because they receive these benefits. I want to confess that I am unsure about whether a public subsidy for the training of workers is the kind of good that can activate duties of fair play. Most philosophers restrict duties of fair play to non-excludable public goods, such as military defence or clean air. In contrast, education is an excludable good. But, for the sake of argument, I will assume that health workers can have duties of fair play to bear a fair share of the costs of their training when other people have assumed costs in order to provide this training for these workers.

While it may be true that health workers do have duties of fair play, it is unclear why these duties would require these workers to refrain from emigrating. Duties of fair play only require the beneficiaries of a good to bear a fair share of the costs of providing this good. So, health workers should bear a fair share of the costs of their education and training. But people can pay these costs in different ways. Some health workers paid tuition when they attended medical school. Many health workers pay taxes. Surveys of physicians who emigrate from African countries to the USA indicate that most of these physicians only immigrate after they have spent more than 5 years in their countries of birth. ${ }^{23}$ Most of these physicians were probably paying taxes and contributing in other ways before they emigrated.

Health workers can pay their debts to their societies even if they emigrate immediately after they finish their training. They 
can do this in two ways. First, suppose that a health worker emigrates right after finishing her training. But, after working abroad for several years, this health worker eventually returns to her native country and finds employment in the healthcare sector. It seems possible for this health worker to pay her fair share after she returns home. Some health workers who emigrate do ultimately return to the countries where they received their training. For example, one survey finds that $50 \%$ of physicians in the UK who emigrated from low-income countries say that they intend to return to their home countries. ${ }^{24}$ Second, health workers can pay their fair share by sending home remittances, which help generate tax revenue through spillover effects on the economy. African physicians in Canada and the USA who were trained in their countries of birth transfer about $\$ 6500$ per year on average to people in their native countries. Michael Clemens estimates that, on average, an African physician who immigrates to the USA or Canada 'can be expected to send home roughly double his or her training cost in unrequited financial transfers' ${ }^{23}$ If health workers can contribute their fair share while they are abroad, then it is false that health workers must remain in their native countries in order to bear their fair share of the costs of their education and training. Of course, public officials may hope that health workers remain and states surely subsidise the cost of medical training because they want to increase the number of health workers in their countries. But health workers lack duties to do whatever public officials hope that they will do.

Some studies do find that the emigration of physicians and other health workers from poor countries on average represent a 'loss of investment' in the training of this worker. ${ }^{25}$ However, it would be a mistake to immediately jump to the conclusion that health workers are failing to satisfy their duties to their compatriots. This is so because health workers lack moral duties to pay back the net present value of this public investment in their education and training. Instead, health workers only have duties to bear a fair share of the costs of their education and training.

To illustrate this point, consider the following case. Imagine that the state subsidies the medical training of Annie who is an intelligent and hardworking medical student. Public officials decide to make this investment because public officials predict that this investment will generate sizable returns. Officials want to encourage Annie and others like her to become practising physicians because there is a shortage of physicians in this country. But Annie has different ideas. Annie completes her medical training, but decides to become a musician instead and, as a result, Annie contributes much less in tax revenue than she otherwise would have contributed. Is Annie doing anything wrong? It appears that the answer to this question is 'no'. While Annie's medical education may benefit her and she plausibly has duties to bear some of the costs of her education, she lacks moral duties to ensure that the public's investment in her education generates the desired or expected returns. Similarly, health workers who receive public subsidies are required to bear a fair share of the costs of their training. Yet there is no reason to believe that a fair share of the costs is equivalent to the desired returns on the public's investment. So, health workers who willingly benefit from public subsidies plausibly have duties of fair play to bear some share of the costs of their training, but we should reject the view that the satisfaction of these duties requires health workers to refrain from emigrating.

Maybe health workers have other duties besides duties of fair play that require them to refrain from emigrating. One possibility is that health workers have duties of gratitude. A person has a duty of gratitude to a benefactor if this person has a duty to appreciate the benefits that the benefactor has provided and have goodwill and respect for her benefactor. ${ }^{26}$ If health workers have duties of gratitude in return for the benefits that they have received, then perhaps these workers violate these duties when they emigrate.

But there is a general problem with appealing to gratitude to explain why health workers are morally required to refrain from emigrating. The problem is that gratitude is indeterminate. A John Simmon observes: 'normally when we acknowledge an obligation of gratitude to another, we are acknowledging only a very general sort of indebtedness'. ${ }^{27}$ If you have a duty of gratitude to someone, you are not necessarily morally required to perform a specific action to satisfy this duty. Gratitude fails to entail moral requirements over particular actions. As an abstract obligation, gratitude only requires that the duty-bearer give greater consideration in moral deliberation to the benefactor's interests and to express goodwill through the duty-bearer's actions. In some contexts, this might mean helping your benefactor, refraining from acting in a manner that is contrary to her interests, or complying with her reasonable requests. But duties of gratitude do not uniquely justify a specific course of action. In other words, duties of gratitude appear to be what philosophers call imperfect duties'. This means that agents have considerable discretion to decide how to satisfy their duties of gratitude.

Here is an illustration. Some people believe that they have duties of gratitude to the universities or colleges where they received their undergraduate education. What do these duties require? It is hard to answer this question. Maybe alumni should donate money to their alma mater institutions. Maybe alumni should encourage other people to attend these institutions. Maybe alumni should become active members of their alumni associations. There does not seem to be a precise answer to the question of what alumni should do to satisfy their duties of gratitude. Generically, alumni must merely express goodwill and respect for their universities and it is up to individuals to decide how they wish to convey these attitudes. If gratitude is an imperfect duty, then even if health workers have duties of gratitude to their compatriots, these workers have discretion over how to satisfy these duties. So, it is unclear at first glance why health workers must abstain from emigrating in order to satisfy their duties of gratitude. Other actions can also express goodwill and respect for the benefactors of these emigrants. Health workers who emigrate could advocate for more international assistance to their home countries, send back remittances, help other immigrants from their country of origin, help form professional networks with people in their home countries and so on.

Let's sum up. Premise 2 of the facilitation argument says that the special obligations of health workers require these workers to remain in their home countries in order to benefit their compatriots instead of emigrating. This premise is false. The special obligations of health workers may require them to contribute a fair share of the costs of their training or to give greater consideration to the interests of their compatriots than they otherwise would. But it is readily possible for workers to satisfy these obligations and emigrate. If so, organisations that recruit health workers abroad are not necessarily facilitating wrongdoing. There is also evidence that emigrants do often bear some significant share of the costs of their training or make some equivalent contribution to the economy and finances of their state. Furthermore, we can interpret the actions of many emigrants as expressing goodwill to their compatriots.

\section{CONCLUSION: PROFESSIONAL CONDUCT AND LAW}

Many people condemn the active recruitment of health workers from poor countries. This condemnation is mistaken. It seems 
that the active recruitment of health workers can and often does satisfy the conditions of Permissible Recruitment.

Of course, the recruitment of health workers from poor countries may still sometimes be morally wrong because it contributes to harmful outcomes or facilitates wrongdoing. But, even in these cases, this recruitment is probably excused. It is extremely difficult for organisations to acquire sufficient information to determine whether the recruitment of health workers violates any moral constraints. The recruiting organisation would need to know whether the emigration of particular health workers would have harmful effects or whether these workers have satisfied their special duties to their compatriots. As we have seen, it is hard to accurately estimate the causal effects of medical emigration. In addition, if health workers can satisfy their duties to their compatriots in multiple ways and these duties are to some extent vague and indeterminate, recruiting organisations are unable to realistically determine whether health workers have satisfied their duties without knowing a great deal about the personal histories of individual health workers. So, even when organisations act impermissibly when they recruit health workers from poor countries, they have excellent excuses relating to epistemic limitations. It is unduly burdensome to expect recruiting organisations to acquire the necessary information to make accurate judgments about whether the departure of particular health workers would bring about harmful effects or whether these health workers have adequately satisfied their special obligations. Although the active recruitment of health workers may be objectively wrong on occasion, recruiting organisations are not usually culpable for this wrongdoing. It is consequently unjustified to blame organisations that recruit health workers from poor countries even if their actions turn out to objectively problematic.

Thus, the active recruitment of health workers is either morally permissible or excused. This conclusion has implications for law, public policy and professional conduct. Some states have tried to discourage the active recruitment of health workers from the poor countries. The British National Health Service has adopted a code of conduct that effectively prohibits the active recruitment of workers from most low-income states. The WHO has also endorsed a code of conduct that discourages member states from recruiting from poor countries with shortages of health workers. ${ }^{28}$ Non-governmental organisations in the USA have similarly urged healthcare organisations to avoid actively recruiting health workers from countries that have shortages of health workers. I have not argued that organisations are morally required to recruit health workers from abroad. It may therefore be morally permissible for organisations to adopt codes of conduct that require them to refrain from recruiting health workers from poor countries. But my argument does largely undermine the positive justification for these codes of conduct. My argument suggests that it is at least morally permissible for organisations to refuse to comply with codes of conduct that discourage the recruitment of health workers from poor countries. Compliance with these codes is morally optional.

Some authors believe that states should punish the recruitment of health workers. One group of researchers claims: 'Active recruitment of health workers from African countries is a systematic and widespread problem throughout Africa and a cause of social alarm: the practice should, therefore, be viewed as an international crime'. ${ }^{4}$ The implication is that states should subject the active recruitment of health workers from Africa to criminal sanctions. We should firmly reject this proposal. The active recruitment of health workers is generally morally permissible and, even when this recruitment is wrong, most recruiting organisations are excused. The criminal law should aim to only sanction actions that are morally impermissible and culpable-only morally impermissible and culpable actions are the fitting objects of state punishment. ${ }^{29}$ So, it is unjust for states to punish the active recruitment of health workers.

\section{Competing interests None.}

Patient consent Obtained.

Provenance and peer review Not commissioned; externally peer reviewed.

\section{REFERENCES}

1 Clemens M, Pettersson G. New data on health care professionals abroad. Hum Resour Health 2008;6:1-11.

2 Eckenwiler L. Care worker migration and transnational justice. Public Health Ethics 2009;2:171-83

3 Attaran A, Walker R. Shopper drug mart or poachers drug mart? CMAJ 2009; 178:265-68.

4 Mills E, Schabas W, Volmink J, et al. Should active recruitment of health care workers from sub-Sahara Africa be viewed as a crime? J Lancet 2008;371:685-8.

5 Hooper C. Adding insult to injury: the healthcare brain drain. J Med Ethics 2008:34:684-7.

6 Scheffler S. The rejection of consequentialism. New York, NY: Oxford University Press, 1995: 41-79.

7 Barry C, Øverland G. The feasible alternatives thesis: kicking away the livelihoods of the global poor. Polit Philos Econ 2012;11:97-119.

8 Brassington I. What's wrong with the brain drain? Dev World Bioeth 2012;12: $113-20$.

9 Bhargava A, Docquier F. HIV pandemic, medical brain drain, and economic development. World Bank Econ Rev 2008;22:345-66.

10 Clemens M. Do visas kill? Health effects of African health professional emigration. Center for Global Development Working Paper Number 114 2007:1-56. http:/l www.cgdev.org/content/publications/detail/13123/ (accessed 28 Feb 2012).

11 Bhargava A, Docquier F, Moullan Y. Modeling the effects of physician emigration on human development. Econ Hum Biol 2011;9:172-83.

12 Chauvet L, Gubert F, Mesplé-Somps S. Are remittances more effective than aid to improve child health? An empirical assessment using inter and intra-country data. In: Lin J, Pleskovic B, eds. People, politics and globalization. Washington, DC: World Bank, 2009: 173-204.

13 Beine M, Docquier F, Oden-Defoort C. A panel data analysis of the brain gain. World Dev 2011;39:523-32.

14 Kruk M, Prescott $M$, Pinho $H$, et al. Are doctors and nurses associated with coverage of essential health services in developing countries? A cross-sectional study. Hum Resour Health 2009:7:1-9.

15 Volqvartz J. The brain drain. The Guardian, 10 March 2005.

16 Lemiere C, Herbst C, Jahanshahi N, et al. Reducing geographical imbalances of health workers in Sub-Sahara Africa. Washington, DC: The World Bank, 2011: 11

17 World Health Organization. The world health report 2006: working together for health. Geneva, Switzerland: The World Health Organization, 2006: 143.

18 Snyder J. Is health worker migration a case of poaching? Am J Bioet 2009;9:3-7.

19 Kirigia J, Gbary A, Muthuri L, et al. The cost of health professionals' brain drain in Kenya. BMC Health Serv Res 2006;6:1-10.

20 Clemens M. Skill flow: a fundamental reconsideration of skilled-worker mobility and development. Center for Global Development Working Paper Number 180 2009:1-47. http://www.cgdev.org/content/publications/detail/1422684/ (accessed 28 Feb 2012)

21 MaAllester M. America is stealing the world's doctors. The New York Times 7 March 2012.

22 Cullity G. Moral free riding. Philos Public Aff 1995;24:3-34.

23 Clemens $M$. The financial consequences of high-skilled emigration: lessons from African doctors abroad. In: Plaza S, Ratha D, eds. Diaspora for development in Africa. Washington, DC: World Bank, 2011: 165-82.

24 Kangasniemia $M$, Winters $A$, Commander $S$. Is the medical brain drain beneficial? Evidence from overseas doctors in the UK. Soc Sci Med 2007;65:915-23.

25 Mills $E$, Kanters $S$, Hagopian A, et al. The financial cost of doctors emigrating from sub-Sahara Africa: human capital analysis. BMJ 2011;343:1-13.

26 Walker A. Political obligation and the argument from gratitude. Philos Public Aff 1988;17:191-211.

27 Simmons A. Moral principles and political obligations. Princeton, NJ: Princeton University Press, 1979: 157-90.

28 The World Health Organization. Global code of practice on the international recruitment of health personnel. http://www.who.int/entity/hrh/migration/code/code en.pdf (accessed 27 Feb 2012).

29 Husak D. Overcriminalization: the limits of the criminal law. New York, NY: Oxford University Press, 2008: 55-119. 